\title{
Research on a Low-Harmonic Nearest Level Modulation Method for Modular Multilevel Converters
}

\author{
Pengfei Hu, a , Xi Wang ${ }^{1}$, Lun Tang ${ }^{1}$, \\ ${ }^{1}$ Sichuan Electrical Power Research Institute, Chengdu, 610027, China \\ aemail: hupengfei01@163.com
}

Keywords: Modular Multilevel Converters; Modulation strategy; Control Strategy

\begin{abstract}
Modular Multilevel Converters (MMC) have been widely applied in medium- and high-voltage applications such as High Voltage Direct Current (HVDC) Transmission. Hence, the modulation method which can generate low harmonic waves with low losses is quite suit for the HVDC condition. This paper proposes a new nearest level modulation (NLM) method for the MMC, with which can decrease the harmonic components. Using this method, the level number of the $\mathrm{MMC}$ is almost doubled and the height of the step in the step wave is halved. The performance of the proposed method is verified by simulations with the PSCAD/EMTDC software.
\end{abstract}

\section{Introduction}

In recent years, the MMC has attracted much attention by academic scholars resulting in large numbers of research publications, which focus on mathematical modeling [1]-[2], modulation methods [3]-[4], control strategies [5], capacitor-voltage balancing [6], and so on. As to the modulation methods for MMCs, there are mainly two types (i.e. pulse width modulations (PWMs) and step wave modulations). Furthermore, PWM methods include the carrier-phase-shifted PWM (CPSPWM), the sub-module unified PWM (SUPWM) and the improved SUPWM, sharing some common features such as high switching frequency, large switching losses and complex implementation process. Among the PWM methods, the CPSPWM and improved SUPWM can generate output voltages with $2 \mathrm{~N}+1$ levels while the conventional SUPWM can only generate output voltages with $\mathrm{N}+1$ levels. As for step wave modulation methods, they mainly include selective harmonic elimination (SHE) method [7] and nearest level modulation (NLM) method [8], which share some common characteristics such as low switching frequency and $\mathrm{N}+1$ levels. Compared to the SHE method, the NLM method does not need a complex calculation of the trigger angles, making NLM method the simplest and most practical modulation method for the MMC. However, in spite of the low switching frequency and simple implementation, the NLM method generates poorer quality waveforms than the CPSPWM and the improved SUPWM methods in case of small numbers of sub-modules. Therefore, the NLM method is mainly applied in high voltage applications where the step number is large enough to improve the output voltage. In order to improve the performance of the NLM method in case of a small number of sub-modules, this paper proposes a modified NLM method with which the maximum level number reaches $2 \mathrm{~N}+1$ as the same as that with the CPSPWM and the improved SUPWM methods.

The outline of this paper is organized as follows: Principles of the MMC are briefly presented in section II. The proposed NLM method is presented and analyzed in section III. In section IV, simulation and results verify the proposed method.

\section{Principles of MMCs}

The topology of a single-phase MMC as shown in Fig. 1 (a) consists of the upper and lower arms, each formed by $\mathrm{N}$ series-connected identical half-bridge sub-modules as well as one arm inductor. Applying Kirchhoff's Voltage Law (KVL) and Kirchhoff's Current Law (KCL) in Fig.1 (a) yields 


$$
\begin{aligned}
& \left\{\begin{array}{l}
u=-u_{U}-L \frac{d i_{U}}{d t}+\frac{1}{2} U_{d c} \\
u=u_{L}+L \frac{d i_{L}}{d t}-\frac{1}{2} U_{d c}
\end{array}\right. \\
& i=i_{L}-i_{U}
\end{aligned}
$$

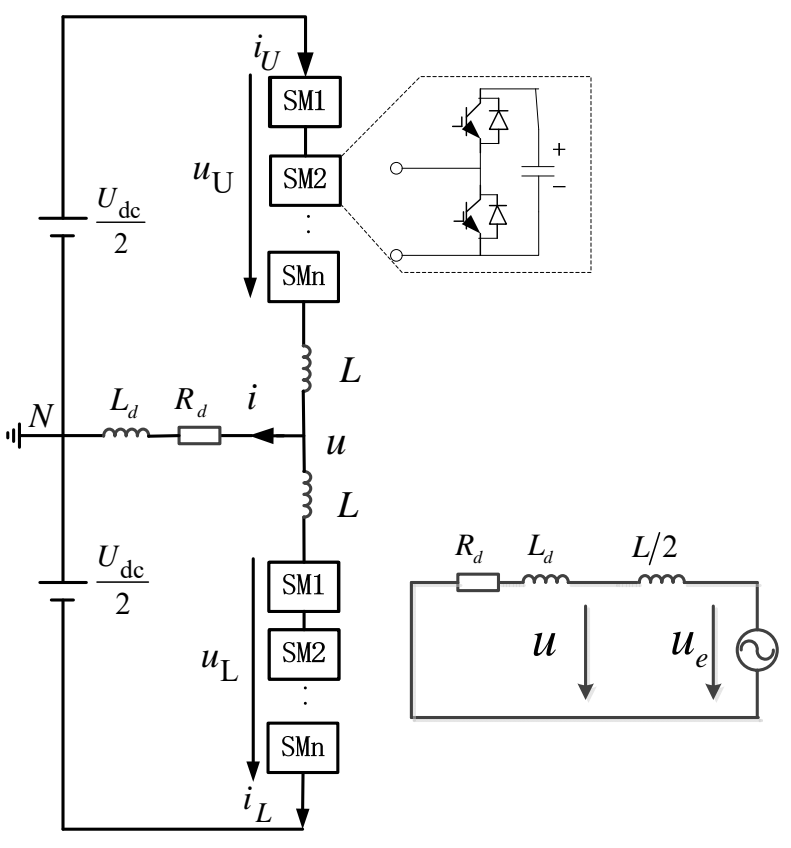

(a)

(b)

Fig.1 (a) Topology of the single-phase MMC; (b) equivalent circuit of the MMC

The equivalent circuit of the MMC is shown in Fig.1 (b). From (1) and (2), the output voltage can be expressed as

$$
u=\frac{1}{2}\left(u_{L}-u_{U}\right)+\frac{L}{2} \frac{d i}{d t}
$$

It can be seen from (3) that the ac electromotive force (EMF) of the MMC is written as

$$
u_{e}=\frac{1}{2}\left(u_{L}-u_{U}\right)
$$

In general, the reference value of ac EMF is expressed as

$$
u_{e}^{r e f}=\frac{m U_{d c}}{2} \cos (\omega t)
$$

where $\mathrm{m}(0 \leqslant \mathrm{~m} \leqslant 1)$ is the modulation index and is the angular frequency. With the conventional NLM method, $\mathrm{N}$ sub-modules are inserted in the circuit. Therefore, the following equation is satisfied on the dc side.

$$
U_{d c}=u_{U}+u_{L}
$$

From (5) to (7), reference voltages of the upper and lower arms are determined by

$$
\left\{\begin{array}{l}
u_{U}^{r e f}=\frac{U_{d c}}{2}[1-m \cos (\omega t)] \\
u_{L}^{r e f}=\frac{U_{d c}}{2}[1+m \cos (\omega t)]
\end{array}\right.
$$

Without redundant sub-modules, the sub-module capacitor voltage and the dc voltage satisfy the following equation. 


$$
U_{d c}=N U_{d}
$$

\section{Low Harmonic NLM Method}

Fig.2 illustrates the principle of the low harmonic NLM method. It is worth noting that the moments of step changing in $u_{L}^{\text {step }}$ and $u_{U}^{\text {step }}$ are not exactly the same. The level numbers of arm voltages are $\mathrm{N}+1$, while the level number of output voltage is $2 \mathrm{~N}+1$. Moreover, the height of the step in $u_{e}^{\text {step }}$ decreases to $0.5 U_{d}$. This little difference leads to substantially increased levels.

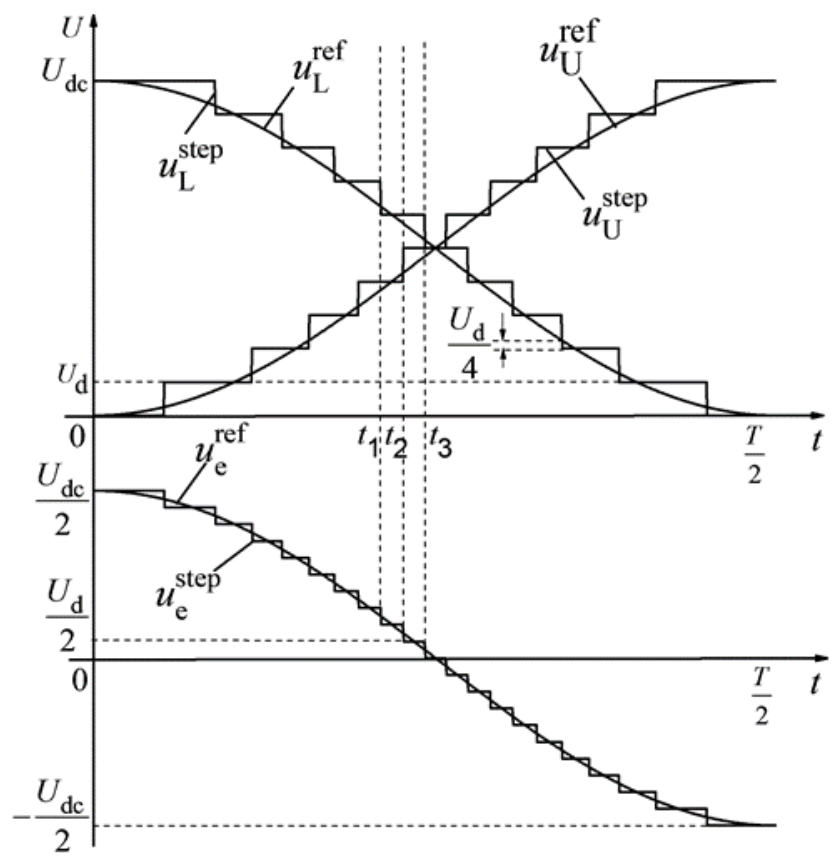

Fig.2 Principles of the low harmonic NLM method

To shift the moments of step changing in the upper- and lower-arm voltages, the arm inserted sub-module numbers should be modified as expressed in (9). The round function (round0.25(x)) means that the real number $\mathrm{x}$ is rounded to the nearest whole number according to the decimal fraction of $\mathrm{x}$. If the decimal fraction of $\mathrm{x}$ is bigger than $0.25, \mathrm{x}$ is rounded up to the next whole number, otherwise rounded down to the next whole number. The overall diagram of the modified NLM method is illustrated in Fig.3.

$$
\left\{\begin{array}{l}
N_{U}=\operatorname{round}_{0.25}\left\{\frac{U_{d c}}{2 U_{d}}[1-m \cos (\omega t)]\right\} \\
N_{L}=\operatorname{round}_{0.25}\left\{\frac{U_{d c}}{2 U_{d}}[1+m \cos (\omega t)]\right\} \\
\text { Equation (7) } \rightarrow \text { round }{ }_{0.25}(x) \rightarrow \begin{array}{c}
\text { RSF } \\
\text { voltage } \\
\text { balancing } \\
\text { algorithm }
\end{array} \rightarrow \text { Firing } \\
\text { pulses }
\end{array}\right.
$$

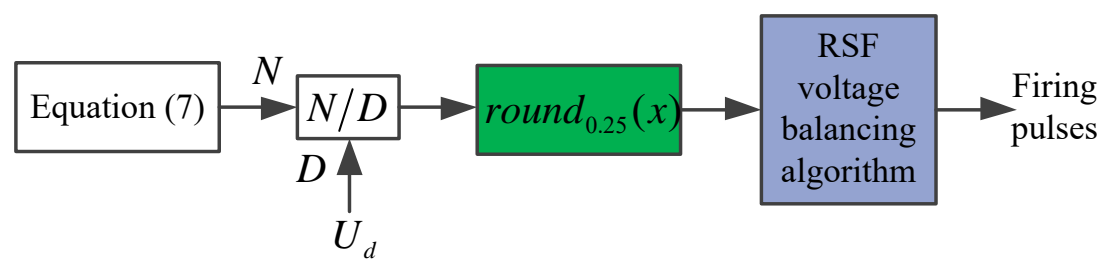

Fig.3 Overall diagram of the modified NLM method

\section{Simulation Results}

The simulation is carried out in the PSCAD/EMTDC software with circuit parameters listed in Table. I. 
Table.I Main circuit parameters for simulations

\begin{tabular}{|l|l|l|}
\hline Items & Symbols & Values \\
\hline Rated AC line-line voltage & $U_{s}$ & $35 \mathrm{kV}$ \\
\hline AC system inductance & $L_{a c}$ & $5 \mathrm{mH}$ \\
\hline AC system resistance & $R_{a c}$ & $0.03 \mathrm{ohm}$ \\
\hline Rated frequency & $f$ & $50 \mathrm{~Hz}$ \\
\hline Rated direct voltage & $U_{d c}$ & $\pm 5 \mathrm{kV}$ \\
\hline Arm inductance & $L$ & $15 \mathrm{mH}$ \\
\hline Total number of SMs per arm & $N$ & 10 \\
\hline Capacitor voltage & $U_{d}$ & $1 \mathrm{kV}$ \\
\hline SM capacitance & $C$ & $7000 \mathrm{uF}$ \\
\hline
\end{tabular}

Fig.4 - Fig.6 show the simulation results with both the conventional and low harmonic NLM methods. When using the conventional NLM method, the three-phase ac voltages on the converter side appear evident distortion and the total harmonic distortion (THD) reaches $5.90 \%$. Since currents flow through the sub-module capacitors, the steps are smoothed by the fluctuation of sub-module capacitor voltages. Anyway, it also can be seen 11 levels in the ac voltages. Besides, the THD of three-phase ac currents reaches $4.86 \%$, which is caused by the harmonics of the ac voltages.

When using the low harmonic NLM method, THDs of the three-phase ac voltages and currents are reduced to $2.02 \%$ and $0.79 \%$, respectively. The voltage steps are too many and small to recognize. Moreover, the sub-module capacitor voltages decrease a little with the low harmonic NLM method as shown in Fig.5. This is because the total number of inserted sub-modules varies between $\mathrm{N}$ and $\mathrm{N}+1$ (i.e. equivalent number is greater than $\mathrm{N}$ ) with the low harmonic NLM method. The variation of the total number of inserted sub-module also leads to larger voltage across the upper and lower arm inductors as shown in Fig.5. Fig.6 shows that the error in id is reduced with the low harmonic NLM method.
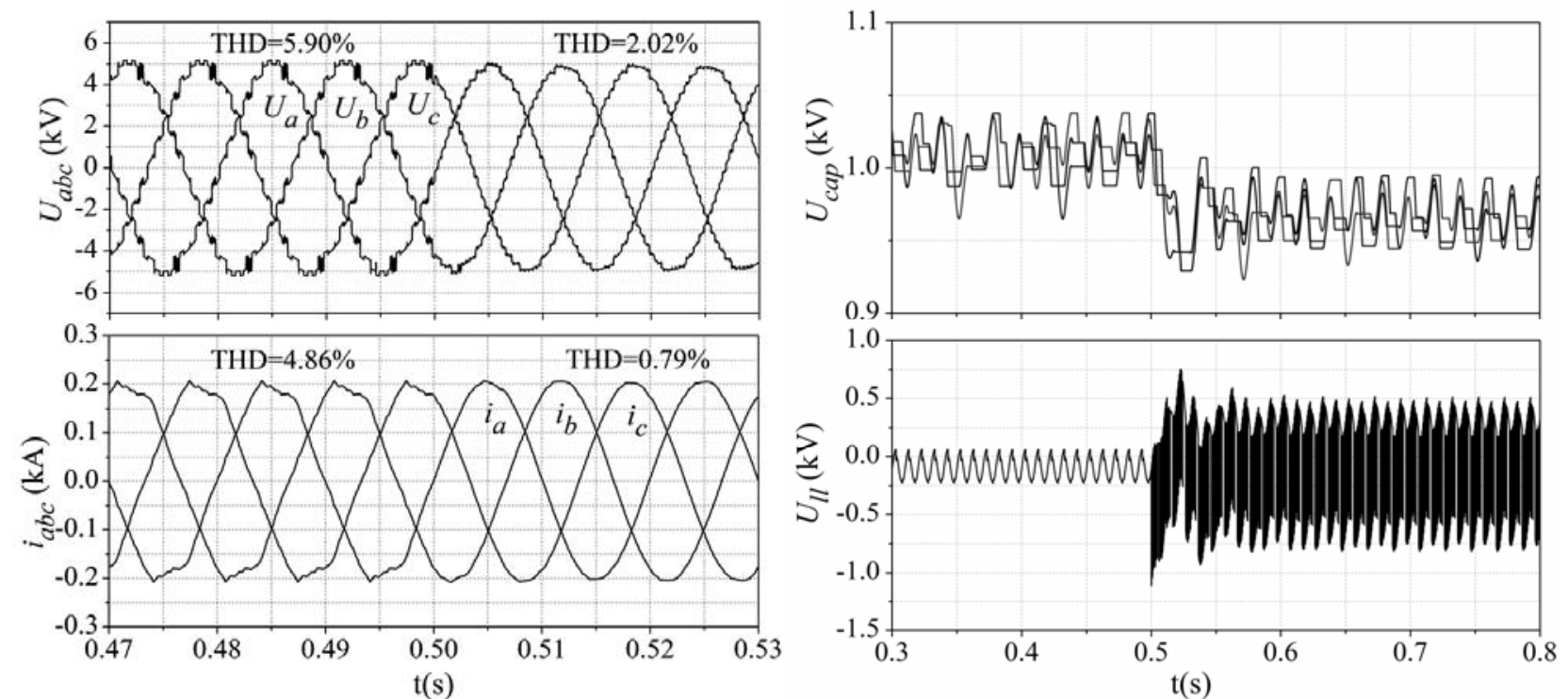

Fig.4 Three-phase ac voltages and currents $\quad$ Fig.5 capacitor voltages and the upper and lower inductor voltage

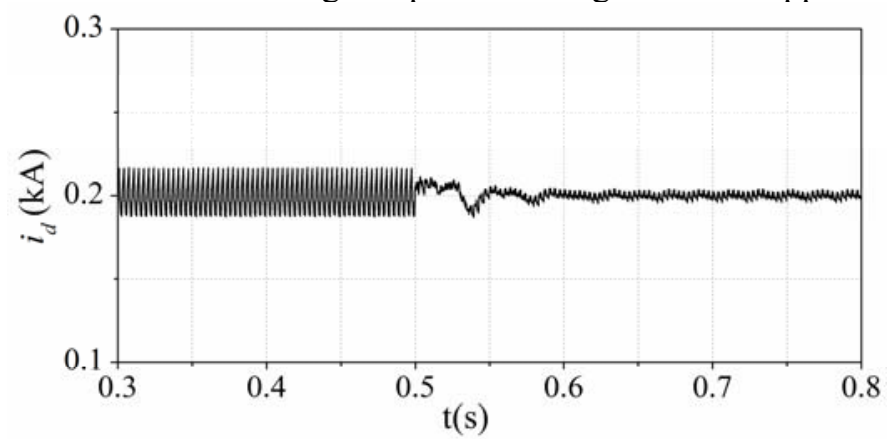

Fig.6 The active current $\left(i_{d}\right)$ 


\section{Conclusion}

A low harmonic NLM method for modular multilevel converters, which can generate $2 \mathrm{~N}+1$ level ac output voltage, is proposed in this paper. The level number of ac output voltage with the low harmonic NLM method is almost double than that with the conventional NLM method. Compared to the improved SUPWM and CPSPWM methods, which can both generate $2 \mathrm{~N}+1$ level ac output voltage, the low harmonic NLM method has lower switching frequency. Principles of the low harmonic NLM method are presented. Simulation results validate the effectiveness of the low harmonic NLM method.

\section{References}

[1] Harnefors, 1.; Antonopoulos, A.; Norrga, S.; Angquist, L.; Nee, H.-P., "Dynamic Analysis of Modular Multilevel Converters," Industrial Electronics, IEEE Transactions on , vol.60, no.7, pp.2526,2537, July 2013

[2] Antonopoulos, A.; Angquist, L.; Harnefors, L.; Ilves, K.; Nee, H.-P., "Global Asymptotic Stability of Modular Multilevel Converters," Industrial Electronics, IEEE Transactions on , vol.61, no.2, pp.603,612, Feb. 2014

[3] Ilves, K.; Antonopoulos, A.; Norrga, S.; Nee, H-.P.; , "A New Modulation Method for the Modular Multilevel Converter Allowing Fundamental Switching Frequency," Power Electronics, IEEE Transactions on, vol.27, no.8, pp.3482-3494, Aug. 2012

[4] Zixin Li; Ping Wang; Haibin Zhu; Zunfang Chu; Yaohua Li, "An Improved Pulse Width Modulation Method for Chopper-Cell-Based Modular Multilevel Converters," Power Electronics, IEEE Transactions on, vol.27, no.8, pp.3472,3481, Aug. 2012

[5] Jiangchao, Q. and M. Saeedifard, Predictive Control of a Modular Multilevel Converter for a Back-to-Back HVDC System. Power Delivery, IEEE Transactions on, 2012. 27(3): p. 1538-1547.

[6] Kui Wang; Yongdong Li; Zedong Zheng; Lie $\mathrm{Xu}$, "Voltage Balancing and Fluctuation-Suppression Methods of Floating Capacitors in a New Modular Multilevel Converter," Industrial Electronics, IEEE Transactions on , vol.60, no.5, pp.1943,1954, May 2013

[7] Ludois, D.C.; Venkataramanan, G., "Simplified Terminal Behavioral Model for a Modular Multilevel Converter," Power Electronics, IEEE Transactions on , vol.29, no.4, pp.1622,1631, April 2014

[8] Minyuan Guan; Zheng Xu; Hairong Chen, "Control and modulation strategies for modular multilevel converter based HVDC system," IECON 2011 - 37th Annual Conference on IEEE Industrial Electronics Society , vol., no., pp.849,854, 7-10 Nov. 2011 